\title{
THE EFFECT OF SIGMODON HISPIDUS ON SPATIAL AND TEMPORAL ACTIVITY OF MICROTUS OCHROGASTER: EVIDENCE FOR COMPETITION ${ }^{1}$
}

\author{
Gregory E. Glass and Norman A. Slade \\ Department of Systematics and Ecology and Museum of Natural History, \\ University of Kansas, Lawrence, Kansas 66045 USA
}

\begin{abstract}
Spatial and temporal activities of cotton rats, Sigmodon hispidus, and prairie voles, Microtus ochrogaster, in an old-field habitat in northeast Kansas, USA were studied for $39 \mathrm{mo}$. During a major portion of the $S$. hispidus reproductive season the species were spatially segregated but co-occurred the rest of the year. Following a local extinction of cotton rats, prairie voles established a resident population in habitats formerly occupied by cotton rats that was greater than or equal to the vole population in areas which had never been occupied by cotton rats. Comparison of vole population size before and after the loss of cotton rats indicated that cotton rats produced a negative effect on vole population size during the period of spatial segregation but not during the period of spatial co-occurrence. Comparison of vole activity patterns indicated that, with the loss of cotton rats, voles shifted their activity during times when the species had co-occurred but not during periods when they were spatially segregated.

Studies of behavioral interactions in a large $(4 \mathrm{~m} \times 4 \mathrm{~m})$ arena with varying densities of vertical wires indicated that during single species tests voles and cotton rats preferred the densest areas. Their diel activity patterns were broadly overlapping. In the presence of nonreproductive cotton rats, voles continued to use the same areas as during the control tests but shifted their temporal activity reducing overlap with cotton rats. Interspecific encounters resulted in voles avoiding cotton rats even in the absence of overt aggression. In the presence of reproductive cotton rats, voles shifted their arena usage toward areas least used by cotton rats. Total nocturnal activity by voles was the same as during the control tests but was restricted to hours when cotton rats were least active. Reproductive cotton rats showed higher levels of interspecific aggression than did nonreproductive cotton rats. Voles in the presence of reproductive cotton rats showed increased frequency of serious wounds and deaths, and decreased mass when compared to voles in the presence of nonreproductive cotton rats.

We conclude that cotton rats produce a negative effect on prairie vole populations but that the interaction is restricted to the cotton rats' reproductive season. Coexistence of the species appears to rely on the seasonality of the interaction, habitat heterogeneity, and the wider habitat tolerance of prairie voles.
\end{abstract}

Key words: allotopy; competition; interspecific aggression; Microtus; resource partitioning; Sigmodon; syntopy.

\section{INTRODUCTION}

The competition model developed independently by Lotka (1925) and Volterra (1926) and expanded by Gause (1934), Hutchinson (1959), MacArthur and Levins $(1964 ; 1967)$, MacArthur $(1969,1972)$, and others has been an impetus for many studies in community ecology. The model predicts that, at equilibrium, two species will not coexist on a common limiting resource unless an increase in the numbers of either species produces a greater negative effect on its own rate of population growth than on the competitor's rate of increase (Pianka 1974). This condition can be met if species partition a limiting resource by specializing on different portions of it. Differential resource use by ecologically similar species, presumably related to resource partitioning, has been well documented (Schoener 1974) but competitive interactions of vertebrate populations in the field have not. Rather, competition is inferred from spatial, temporal, and re-

${ }^{1}$ Manuscript received 30 November 1978; revised 22 June 1979; accepted 22 June 1979. source usage patterns (Grant 1972, Cody 1974, Wiens 1977); assuming interspecific competition from these patterns is tautological (Peters 1976).

Comparative studies of small mammal communities have relied heavily on competition theory while documenting differential resource usage patterns among species (e.g., Rosenzweig and Winakur 1969, Brown and Lieberman 1973, Husar 1976, M'Closkey 1976, Whitford 1976, Hawes 1977, Holbrook 1978). However only a few studies have attempted to demonstrate that interspecific competition is responsible for the observed differences' (Koplin and Hoffmann 1968, Grant 1969, 1970, 1971, Morris and Grant 1972, Petersen 1973, M'Closkey and Fieldwick 1975, Schroder and Rosenzweig 1975, Cameron 1977, Krebs 1977). The results of these tests suggest that the importance of interspecific competition in small mammal community structure is variable. While Koplin and Hoffmann (1968), Grant (1969, 1971), Morris and Grant (1972), and Petersen (1973) reported demographic changes and resource usage shifts supporting interspecific competition, M'Closkey and Fieldwick (1975), Schroder and Rosenzweig (1975), Cameron (1977), and 
Krebs (1977) found no evidence to support the hypothesis that differences in resource usage were due to competition.

It has been argued that the failure to demonstrate interspecific competition may be due to evolutionary divergence following initial competitive interactions (MacArthur 1972, Schoener 1974, Schroder and Rosenzweig 1975). Without historical evidence such hypotheses are untestable, but given that they might be true, the most likely situation where interspecific competition could be demonstrated is where two ecologically similar species have recently come into contact.

Cockrum (1948) studied the northward dispersal of Sigmodon hispidus Say and Ord, the cotton rat, in Kansas from 1933 until 1947. Martin (1956) and Terman (1974) noted that this expansion coincided with declines in the abundance of Microtus ochrogaster (Wagner), the prairie vole, and concluded that interspecific competition with $S$. hispidus was responsible for the $M$. ochrogaster population declines. This hypothesis was supported by Frydendall's (1969) study in central Kansas in which he demonstrated that, in the presence of $S$. hispidus, $M$. ochrogaster failed to occupy remnant prairie grassland but with the decline of S. hispidus, M. ochrogaster from peripheral habitat migrated into the grassland. Martin (1956) suggested that $S$. hispidus excluded $M$. ochrogaster from suitable habitat through aggressive interference. Terman (1974) studied behavioral interactions of $S$. hispidus and $M$. ochrogaster and reported that $S$. hispidus were aggressive towards $M$. ochrogaster in laboratory enclosures but that the frequency of interspecific contact determined the degree of exclusion between species in the field.

This paper reports the results of a laboratory study of spatial and temporal activity patterns of mixed and single species groups of $M$. ochrogaster and S. hispidus. Concurrently, (1973-1977) the spatial and temporal patterns of the two species in the field were studied and the response of the vole population following the temporary extinction of cotton rats in the field is described: Our purpose is to determine if there is evidence of interspecific competition between two ecologically similar species which have recently come into contact.

\section{Methods}

From 23 November 1973 until 12 February 1977 small mammals were livetrapped on a study site at the Nelson Environmental Studies Area, Jefferson County, Kansas, $14.5 \mathrm{~km}$ northeast of Lawrence, Douglas County, Kansas.

We trapped in a 100 station, square grid located in a typical old field, abandoned in 1969. Forty-six trap stations were located in a brome grass (Bromus inermis) and bluegrass (Poa pratensis) pasture which was being invaded by various forbs and shrubs, most prominently, goldenrod (Solidago spp.), honey locust
(Gleditsia triacanthos), Osage orange (Maclura pomifera), and dogwood (Cornus drummondii). Fiftyfour trap stations were in an abandoned, terraced grain sorghum field containing several weedy annuals and perennials, notably, foxtail (Setaria spp.), sunflower (Helianthus annuus), and aster (Aster multiflorus). During the study, cotton rats were restricted primarily to the brome grass-bluegrass pasture and the terraces with heavy growths of foxtail and sunflowers.

The trapping grid covered 2.25 ha, including a 7.5$\mathrm{m}$ boundary strip, with trapping stations spaced at 15$m$ intervals. Two live traps, one modified Fitch trap (Rose 1973) and one collapsible Sherman trap $(23 \mathrm{~cm} \times$ $9 \mathrm{~cm} \times 8 \mathrm{~cm}$ ), were placed at each station and baited with a mixture of feed grains (Rose 1973). Nesting material was added to the traps from October until April. Traps were set three consecutive days every 2 wk during the cotton rat reproductive season (AprilDecember). During the rest of the year traps were set at either 2- or 3-wk intervals, avoiding extremely cold weather, to reduce potential trap mortality and avoid periods of cotton rat inactivity (Dunaway and Kaye 1961). Traps were locked open and left in place between trapping periods.

Captured cotton rats were marked with ear tags and the trap station coordinates, mass, sex, and external reproductive condition recorded before release at the capture site. Males were recorded as reproductively active if their testes were scrotal. Females with perforate vaginas and medium or large nipples were recorded as reproductive. After 1975 prairie voles were toe clipped for identification. Data recorded were the same as for cotton rats.

\section{Spatial association analysis}

To measure spatial association between cotton rats and prairie voles, the numbers of captures of each species at the 100 trap stations were used to calculate Kendall's coefficient of rank correlation $(\tau)$ for each of 31 trapping periods spanning a period of $19 \mathrm{mo}$. Spatial exclusion between the species would be indicated by $\tau$ 's which were significantly $<0$. Since negative correlations might also be due to trap saturation, (i.e., traps being unavailable because they were already sprung), the numbers of times traps were found open was recorded for all trapping periods. If trap saturation were responsible for trapping periods with negative $\tau$ 's, indicating allotopy, then these periods should have fewer open traps than periods with nonnegative coefficients, i.e., times of syntopy.

\section{Temporal activity}

Traps were checked shortly after sunrise and prior to sunset. Animals caught at sunrise were crepuscular or nocturnal while animals caught at sunset were diurnal. Proportions of nocturnal and diurnal cotton rats and prairie voles were compared by $\chi^{2}$ tests of inde- 
pendence. Vole and cotton rat captures during times of allotopy and syntopy were analyzed separately.

If differences in temporal activity were responses to competitive interactions, then the absence of cotton rats should have resulted in an expansion in prairie vole activity throughout the day. To test for temporal partitioning the numbers of diurnal and nocturnal vole captures were compared when cotton rats were present (prior to June 1975, see below) and when they were absent. Vole activity patterns in the presence and absence of cotton rats were analyzed separately for the periods corresponding to syntopy (roughly December to May) and allotopy (May to December) using $\chi^{2}$ tests of independence.

\section{Vole response to cotton rat extinction}

In June 1975 cotton rats disappeared from the study site and prairie voles moved into the areas previously occupied by cotton rats. If cotton rat habitat were marginal for prairie voles, habitat segregation between voles and cotton rats would not have indicated competition. Since voles dispersing into marginal habitat tend to be demographically distinct from resident populations (Myers and Krebs 1971, Krebs et al. 1976, Tamarin 1978, Gaines et al. 1979), the suitability, for voles, of cotton rat habitat was tested by comparing demographic patterns of the voles in those areas with contemporaneous vole populations in non-cotton rat habitat. Three demographic indices were examined; mass structure (as a measure of age), sex ratios of the populations, and the proportion of reproductive adults. Mass structure of the vole populations from the cotton rat and non-cotton rat habitats were compared using a Kolmogorov-Smirnov two-sample test of masses of each animal at first capture in a trapping period. Sex ratios for the two groups were compared using a $\chi^{2}$ test of independence. The proportions of reproductive adults of each sex, based on external examination, in the two populations were tested for significant differences by $\chi^{2}$ tests of independence.

\section{Laboratory study}

Direct observation of behavioral interactions between these two species in the field was not possible so laboratory experiments were designed to observe behavioral interactions. The goal of these experiments was to determine if the interactions were suggestive of aggressive interference, if they were an effective means for cotton rats to reduce prairie vole populations, and if they resulted in spatial segregation of the species.

A $4 \mathrm{~m} \times 4 \mathrm{~m}$ arena of $1.3-\mathrm{cm}$ plywood, $60 \mathrm{~cm}$ high, was built so the top of the arena was $1.35 \mathrm{~m}$ above the ground. The top and bottom of the arena were each fitted with eight $0.9 \mathrm{~m} \times 2 \mathrm{~m}$ frames covered with 0.64- $\mathrm{cm}$ mesh hardware cloth. Two centrally located frames, $0.4 \mathrm{~m} \times 2 \mathrm{~m}$, on the top and bottom provided complete closure of the arena. All wooden portions of the arena were coated with a clear sealant to prevent saturation by water, feces, and urine. To simulate vertical plant stems, 13-gauge cold-rolled steel wire was cut to $1-\mathrm{m}$ lengths, hooked through the top screens, passed through the arena, and confined within the mesh in the bottom screens. This permitted animals to pass between the wires, pushing them out of the way if necessary, without permanent alteration of wire density or position. The arena was divided into four quadrants of approximately equal size (range 3.1-3.2 $\mathrm{m}^{2}$ ). Wires were hung in parallel rows within each quadrant, with wire densities in the four quadrants of 2755 wires $/ \mathrm{m}^{2}, 2028$ wires $/ \mathrm{m}^{2}, 1222$ wires $/ \mathrm{m}^{2}$, and 441 wires $/ \mathrm{m}^{2}$.

Eight steel cans (number 10) with two openings for entrances, filled with cotton batt, were used as nest boxes. These were placed in 0.5 -m-wide passage areas between quadrants. Water bottles were placed $\approx 0.9$ $\mathrm{m}$ from each corner of the arena and attached to the outside wall; sipper tubes passed through holes in the wall $2 \mathrm{~cm}$ above the arena floor. Purina Rat Chow Laboratory pellets (provided ad libitum) were scattered throughout each quadrant of the arena.

Four trays $(2 \mathrm{~m} \times 2 \mathrm{~m}) 35 \mathrm{~cm}$ below the arena bottom, each corresponding to an arena quadrant, collected feces, urine, and excess food. The entire arena was covered with translucent nylon cloth to reduce light intensity to approximate field conditions.

Wild-caught adult ( $>30 \mathrm{~g}$ for $M$. ochrogaster and $>60 \mathrm{~g}$ for $S$. hispidus) females were brought to the laboratory and held individually in $23 \mathrm{~cm} \times 23 \mathrm{~cm} \times$ $40 \mathrm{~cm}$ wire cages and provided Rat Chow and water ad libitum. Cotton batt was provided for nesting material. Six wire cages were placed inside a larger $(69$ $\mathrm{cm} \times 69 \mathrm{~cm} \times 102 \mathrm{~cm}$ ) holding cage. One holding cage was used for prairie voles and the other for cotton rats. Thus, visual communication between conspecifics and olfactory and auditory communication between species were possible but tactile encounters were prevented. Animals were held in the same room as the arena for 2-3 wk to permit acclimatization. Light entered from a wall of shaded windows maintaining the animals on a natural day-length cycle.

Three test procedures were used; single species controls in which six conspecifics were observed in the arena, and two experimental procedures.

It has been suggested (Iverson and Turner 1972, Turner and Iverson 1973, Turner et al. 1975) that both intra- and interspecific levels of aggression are related to reproductive activity in seasonally reproductive small mammals. Therefore, the two experimental procedures consisted of comparing interspecific interactions during the cotton rat reproductive and nonreproductive seasons. Experimental groups consisted of three prairie voles and either three reproductive (reproductive tests) or three nonreproductive cotton rats (nonreproductive tests). Three replicates of the controls, nonreproductive and reproductive tests were 
performed. At the start of each experiment the animals were individually marked with Diazol dye for visual recognition. Cotton rats were ear tagged and prairie voles toe clipped to ensure proper identification at the termination of the experiment. Each animal was weighed, and examined as to its external reproductive condition and the presence of wounds and scars. The animals were placed in the arena and permitted to acclimatize for $48 \mathrm{~h}$. After this time the trays for collecting feces were placed below the arena. For the next $7 \mathrm{~d}$ animals were observed from a raised platform ( $2 \mathrm{~m}$ above the arena) at randomly selected .5-h intervals during the day. Every $3 \mathrm{~min}$ each animal's location, activity and any behavioral interactions were noted. Behaviors recorded followed Turner and Iverson (1973). During daylight hours animals were observed unaided. After dark, observations were made using a 25-watt red light (Terman 1974) suspended 30 $\mathrm{cm}$ below the arena, and a Startron nightscope.

At the termination of each experiment the animals were removed, weighed, and scars, wounds, and general external condition noted. No change in external condition during test procedures was scored as 0 . Minor wounds were scored as I (wound on tail, torn pinnae) or II (wound $<1 \mathrm{~cm}^{2}$, no damage to underlying tissue). Severe wounds were scored as III (wound $\geqslant$ $1 \mathrm{~cm}^{2}$, minor damage to underlying tissue) or IV ( $>1$ $\mathrm{cm}^{2}$, extensive lesions and damage to underlying tissues).

In addition to wounding, changes in body mass during test procedures were examined for both species. The means and variances of the initial body masses of prairie voles and cotton rats were not significantly different between test procedures. Therefore, differences in body mass at the termination of trials were assumed due to test procedures.

The trays corresponding to arena quadrants were removed and feces were collected and sorted as to species, dried, and weighed. The proportion by mass of feces in each quadrant was calculated and changes in the proportion of feces in the quadrants for different test procedures were tested with a two-way ANOVA, following an arcsin transformation (Rohlf and Sokal 1969, page 129) of the percentages to correct for heteroscedasticity.

Temporal data from the laboratory were compared with the field data by recording the numbers of prairie voles and cotton rats seen during daylight and dark hours. $\chi^{2}$ tests of independence were used to test for significant differences between species and test procedures. To compare prairie vole activity in the presence and absence of cotton rats, the numbers of voles observed during daylight and dark hours in the control test were compared to those during reproductive and nonreproductive tests.

To analyze the temporal activity patterns of both species under control and experimental conditions on a more finely divided time scale, the numbers of ani-

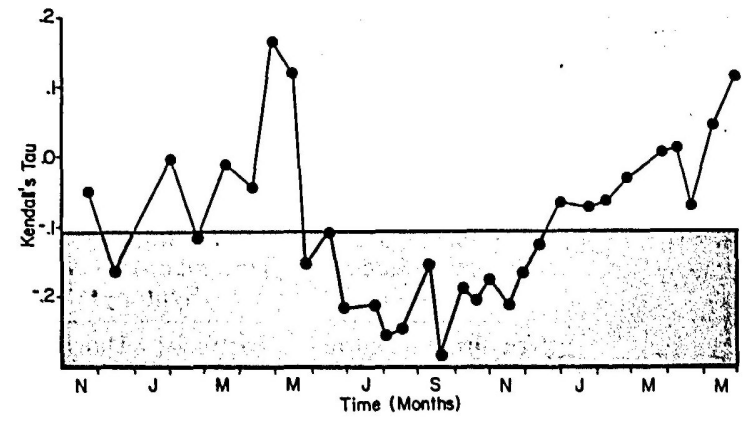

FIG. 1. Spatial association index (Kendall's Tau) for cotton rats and prairie voles. Horizontal line at $\tau=-0.110$ indicates significant spatial segregation (allotopy).

mals of each species observed per observation period were recorded. Using these data, the relative proportion of animals observed during each hour in the 24-h day was calculated, and the results for the control, nonreproductive, and reproductive tests were compared by inspection of graphs.

\section{RESULTS}

\section{Field study}

Spatial analysis.-Spatial association between $M$. ochrogaster and S. hispidus from 22 November 1973 until 21 May 1975 is shown in Fig. 1. The null hypotheses tested were that $\tau$ was $\geqslant 0$. Significant negative rank correlation coefficients, indicating allotopy, were found for 14 December 1973, 22 February 1974, and from 23 May 1974 until 11 December 1974 (except for 14 June when $\tau=-0.109 ; P=.054$ ). During the remainder of the study no $\tau$ was significantly $<0$. A runs test (Conover 1971) revealed that the pattern of trapping periods with negative and nonnegative coefficients differed from random $(P<.005)$ and that times of allotopy and syntopy were seasonally clumped during the study period.

Frequencies of open traps during allotopy and syn-

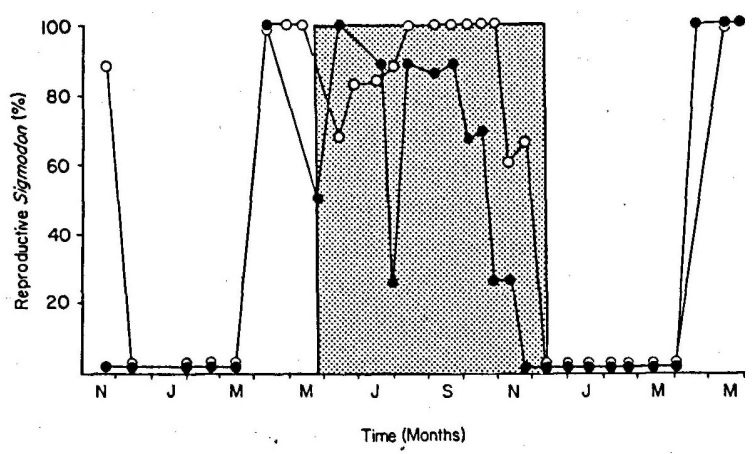

FIG. 2. Relationship between period of spatial segregation (stippled area) and the percentage of reproductive adult male $(\Theta)$ and female $(O)$ cotton rats. 
TABLE 1. $M$. ochrogaster and $S$. hispidus activity (numbers captured) in the field during allotopy and syntopy and $M$. ochrogaster activity (numbers captured) during times before $(+$ Sigmodon) and after the disappearance (- Sigmodon) of $S$. hispidus.

\begin{tabular}{|c|c|c|c|c|}
\hline & \multicolumn{2}{|c|}{$\begin{array}{l}\text { Number captured } \\
\text { during late } \\
\text { May-mid December } \\
\text { (Allotopy) }\end{array}$} & \multicolumn{2}{|c|}{$\begin{array}{c}\text { Numbers captured } \\
\text { during late } \\
\text { December-mid May } \\
\text { (Syntopy) }\end{array}$} \\
\hline & Nocturnal & Diurnal & Nocturnal & Diurnal \\
\hline \multirow[t]{2}{*}{$\begin{array}{l}\text { Sigmodon } \\
\text { Microtus }\end{array}$} & $\begin{array}{l}108 \\
225\end{array}$ & $\begin{array}{r}100 \\
50\end{array}$ & $\begin{array}{r}84 \\
242\end{array}$ & $\begin{array}{r}63 \\
113\end{array}$ \\
\hline & \multicolumn{4}{|c|}{$\chi^{2}=49.432, \alpha<.005 \chi^{2}=5.551, \alpha<.025$} \\
\hline \multirow[t]{2}{*}{$\begin{array}{l}\text { (+) Sigmodon } \\
(-) \text { Sigmodon }\end{array}$} & $\begin{array}{l}225 \\
240\end{array}$ & $\begin{array}{l}50 \\
72\end{array}$ & $\begin{array}{l}242 \\
478\end{array}$ & $\begin{array}{l}113 \\
303\end{array}$ \\
\hline & \multicolumn{2}{|c|}{$\chi^{2}=2.127, \alpha>.100$} & \multicolumn{2}{|c|}{$\chi^{2}=5.102, \alpha<.025$} \\
\hline
\end{tabular}

topy suggested that trap saturation was not the cause of the negative correlation coefficients. When $\tau$ was negative $95.4 \%$ of the traps capturing either species were open more than half the times they were checked. When $\tau$ was nonnegative $90.9 \%$ of the traps were open more than half the time they were checked. Given that the trend for traps being open is in the "wrong" direction from expected, it is unlikely that trap saturation was responsible for the negative coefficients of spatial association.

Fig. 2 shows the relationship between the cotton rat reproductive cycle and the major period of allotopy, 23 May to 11 December 1974. The coefficients of spatial association were significantly negative after the onset of reproduction in April, as the cotton rat population began to increase (Glass and Slade 1980, in press) and remained significantly negative until the termination of reproduction in December.

Thus, the trapping results indicate that spatial segregation occurs between prairie voles and cotton rats, but is primarily restricted to the cotton rat breeding season. Interactions between the species do not result simply in cotton rats displacing prairie voles through nonseasonal aggressive interference as suggested by Martin (1956), Frydendall (1969), and Baker (1971).

Temporal activity.-How, then, do individuals of the two species respond to one another outside the cotton rat breeding season? Two possibilities exist; either they do not interact, or the interaction results in something other than spatial partitioning.

Observations of behavioral interactions in the laboratory suggest that interactions do occur during syntopy (see below) and $\chi^{2}$ tests of independence between proportions of cotton rats and prairie voles which were diurnal and nocturnal suggest that temporal partitioning may have occurred.

During allotopy $48.1 \%$ of the cotton rats and $18.2 \%$ of the prairie voles captured were diurnal. During syntopy $42.9 \%$ of the cotton rats and $31.8 \%$ of the prairie voles were diurnal. During both periods of time the proportion of diurnal and nocturnal individuals differed between species (Table 1).

If interspecific differences were due to temporal partitioning then the disappearance of cotton rats should result in prairie vole activity being more evenly distributed between day and night. Prairie vole activity before the cotton rat extinction was primarily nocturnal $(81.8 \%)$ during allotopy. For comparable months after the cotton rat extinction, $76.9 \%$ of the vole captures occurred at night, a nonsignificant difference $(\alpha>$ .1 , Table 1 ). During syntopy $68.2 \%$ of the voles were nocturnal while during the same months in the absence of cotton rats $61.2 \%$ of the voles were nocturnal, a significant difference $(\alpha<.025$, Table 1). Temporal differences between cotton rats and prairie voles during allotopy were not due to temporal partitioning because the extinction of cotton rats did not produce a significant temporal shift in vole activity. During times of former syntopy the extinction of cotton rats was followed by significant shifts in the voles' activity pattern with their activity more evenly distributed between day and night, a response suggesting temporal partitioning.

Effect of Sigmodon extinction on Microtus numbers.-The number of vole captures in habitat occupied by cotton rats prior to their extinction (November 1973 to June 1975) was compared with the number of captures in those habitats following the cotton rat extinction (June 1975 to February 1977). As a control, the number of vole captures in non-cotton rat habitats was compared with numbers from cotton rat habitats.

Following a population low in autumn 1973 the vole populations in both areas began to increase in the early winter 1973-1974 (Fig. 3). The numbers of voles in cotton rat habitat tended to lag behind the numbers in non-cotton rat habitat until early spring when they surpassed the decreasing vole populations in the non-cotton rat habitat. Shortly afterwards, allotopy began (stippled area Fig. 3) and the vole population in the cotton rat habitat declined abruptly below that of the vole population in the other habitat. It remained less than the number of voles in the non-cotton rat habitat until the termination of allotopy when the vole population in the cotton rat habitat increased above that of the non-cotton rat habitat. In late May 1975 with the onset of breeding and an increasing cotton rat population, the vole population began to decline as it had in 1974. However, shortly afterward, the cotton rat population disappeared. Instead of continuing to decline the vole population in the cotton rat habitat remained at or above the level of the vole population in the non-cotton rat habitat. The winter of 1975-1976 was a period of peak abundance for prairie voles. This was due to high numbers of voles in cotton rat habitat since the numbers of voles in the non-cotton rat habitat did not differ greatly from the numbers of voles captured in these areas during previous seasonal peaks in winter 1973-1974 or autumn 1974 (Fig. 3). Thus, the 


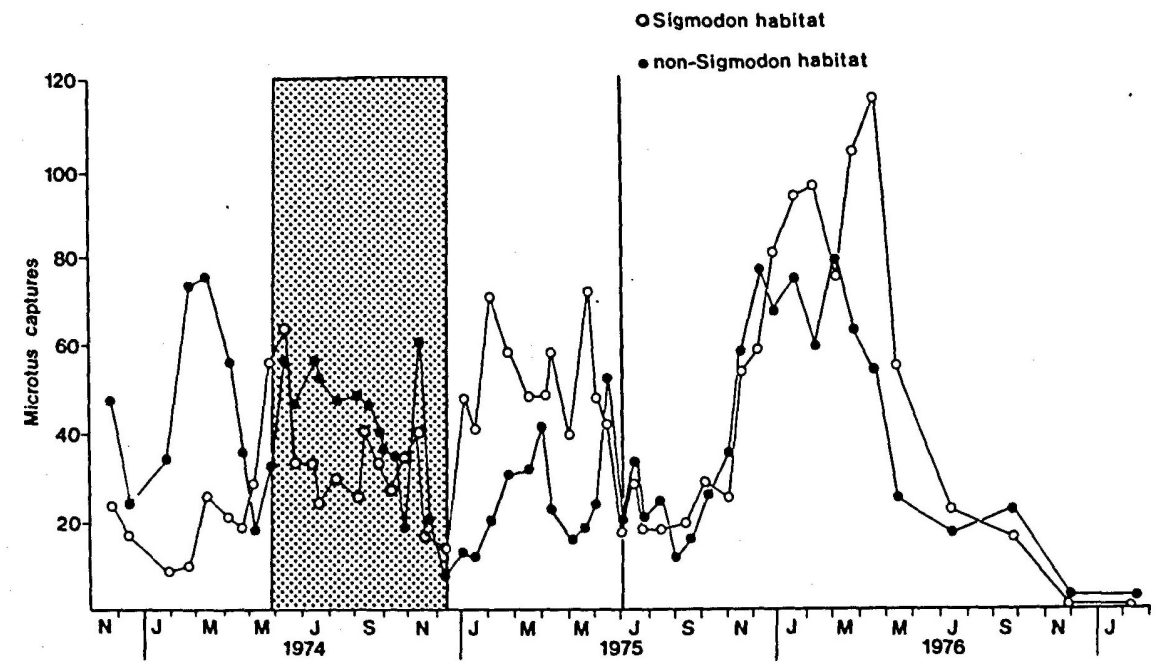

FIG. 3. Numbers of prairie vole captures in the cotton rat habitat $(O)$ and non-cotton rat habitat ( $)$. Stippled area represents the period of allotopy. Vertical line in July 1975 indicates time of cotton rat disappearance from the study area.

absence of cotton rats was accompanied by an increase in prairie vole numbers in the area previously occupied by cotton rats while vole population in noncotton rat habitat did not seem to be numerically affected by either the disappearance of cotton rats or the factors responsible for the rats' extinction.

Possibly prairie voles captured in cotton rat habitat were moving into a dispersal sink (Lidicker 1975) following the loss of cotton rats. Since a dispersal sink may be ". . . marginal or even unsuitable habitat in which at least short-term survival is possible" (Lidicker 1975) and must “. . . permanently remove animals from the main population" (Tamarin 1978), spatial exclusion by cotton rats is not strong evidence for interspecific competition. However, dispersing microtines are frequently characterized by trends towards smaller individuals, more males and fewer reproductive adults, especially females (Myers and Krebs 1971, Lidicker 1975, Krebs et al. 1976, Gaines et al. 1979). These patterns have been found in all reported microtine population studies; however Joule and Cameron (1975) note they may not be present in all rodents. While their dispersing Reithrodontomys populations were structurally different from the resident populations, dispersing Sigmodon populations were not. Our unpublished data on movements indicate that Sigmodon are much more mobile than Reithrodontomys or Microtus so some differences might be expected.

None of the 19 statistical comparisons of vole mass structure from cotton rat habitat and non-cotton rat habitat showed significantly $(\alpha>.1)$. smaller voles in the former group. Comparisons of sex ratios in prairie vole populations from cotton rat habitat and non-cotton rat habitat showed that there was no trapping period with a significant excess of males in the cotton rat habitat $(\alpha>.2)$ which again, does not support the dispersal sink hypothesis. No significant $(\alpha>.15)$ deficiency of reproductives was found in 14 comparisons of reproductive adult males or females from the two areas.

Thus, there was no demographic evidence to support the hypothesis that habitat previously occupied by cotton rats served as dispersal sinks for prairie voles from other habitats. Rather, prairie voles seemed to have established a resident population in the areas soon after the disappearance of the cotton

TABLE 2. Mean relative use (\%) of the four arena quadrants by $M$. ochrogaster and $S$. hispidus during control, nonreproductive, and reproductive tests. Areas I-IV are arena quadrants; I has the highest wire density and IV the lowest. Control is the single species test procedure; Nonreproductive, the test using nonreproductive $S$. hispidus; and Reproductive, the test using reproductive $S$. hispidus. Three replicates were made of each test procedure.

\begin{tabular}{|c|c|c|c|c|c|c|c|c|}
\hline \multirow[b]{2}{*}{ Area } & \multicolumn{4}{|c|}{ M. ochrogaster \% activity } & \multicolumn{4}{|c|}{ S. hispidus $\%$ activity } \\
\hline & I & II & III & IV & $I$ & II & III & IV \\
\hline $\begin{array}{l}\text { Control } \\
\text { Nonreproductive } \\
\text { Reproductive }\end{array}$ & $\begin{array}{l}51.02 \\
56.43 \\
38.92\end{array}$ & $\begin{array}{l}26.96 \\
37.24 \\
28.94\end{array}$ & $\begin{array}{r}16.26 \\
4.06 \\
16.21\end{array}$ & $\begin{array}{r}5.79 \\
2.27 \\
15.92\end{array}$ & $\begin{array}{l}21.71 \\
30.79 \\
29.70\end{array}$ & $\begin{array}{l}24.57 \\
27.36 \\
21.81\end{array}$ & $\begin{array}{l}27.45 \\
31.63 \\
32.13\end{array}$ & $\begin{array}{l}15.28 \\
10.22 \\
16.33\end{array}$ \\
\hline
\end{tabular}


TABLE 3. ANOVA comparison of $M$. ochrogaster arena quadrant (I-IV) preferences during control, nonreproductive and reproductive tests. See Table 2 for explanations of terms.

\begin{tabular}{lrrrrr}
\hline \hline \multicolumn{7}{c}{ df } & \multicolumn{1}{c}{$S S$} & $M S$ & \multicolumn{1}{c}{$F$} & $P$ \\
\hline Control vs. nonreproductive & & & \\
Tests & 1 & 10.297 & 10.297 & NS & \\
Areas & 3 & 5317.549 & 1772.516 & 42.265 & $<.001^{* * *}$ \\
Interaction & 3 & 304.907 & 101.636 & 2.420 & $<.250$ \\
Error & 16 & 671.018 & 41.939 & & \\
Control vs. reproductive & & & \\
Tests & 1 & 2.836 & 2.836 & NS & \\
Areas & 3 & 1609.695 & 536.565 & 11.813 & $<.001^{* * *}$ \\
Interaction & 3 & 558.497 & 186.166 & 4.098 & $<.025^{*}$ \\
Error & 16 & 726.772 & 45.423 & & \\
Reproductive vs. nonreproductive & & \\
Tests & 1 & 48.082 & 48.082 & NS & \\
Areas & 3 & 3456.267 & 1152.089 & 16.956 & $<.001^{* * *}$ \\
Interaction & 3 & 708.790 & 236.263 & 3.477 & $<.050^{*}$ \\
Error & 16 & 1087.127 & 67.946 & & \\
\hline \multicolumn{7}{l}{} \\
\hline
\end{tabular}

rats and maintained numbers greater than or equal to those in the area not occupied by cotton rats. The failure of prairie voles to maintain high population numbers in cotton rat habitat during allotopy from May to December 1974 represented a real decline in the potential size of prairie vole populations.

\section{Laboratory study}

Spatial usage.-Similar conclusions concerning use of space were drawn from visual observations and fecal pellet counts so only fecal pellet distribution data are presented here (Table 2). During single species tests, prairie vole activity was concentrated in the two areas with the highest wire densities $(78 \%)$ with only $5 \%$ of activity in the area of lowest wire density. During the nonreproductive tests the pattern remained essentially unchanged, though there was an even greater tendency to use the areas with highest wire densities. However, during reproductive tests, prairie vole use decreased in the two high-density quadrants (68\%) and increased in the lowest density quadrant (16\%). During all three tests cotton rats tended to show approximately equal use of the three quadrants with the highest wire densities but consistently used the quadrant with the lowest wire density less often. The equal use of the three areas appeared to be related to social spacing between individual cotton rats.

Analysis of variance of arcsin-transformed proportions showed that for all comparisons there was a significant effect of wire density (Areas) on spatial usage by prairie voles (Table 3). Use of percentages and the arcsin transformation limited test totals to between 90 and 120 . As a result, total activity levels under different test conditions could not be meaningfully compared and the test sums of squares, mean squares, etc. (Table 3) are of no consequence. Significant shifts of spatial usage patterns in the arena would have been indicated by significant interaction terms between areas and treatments in the ANOVA. Comparisons of control and nonreproductive tests showed that prairie voles did not change their spatial usage patterns when sharing the arena with nonreproductive cotton rats. However, prairie vole spatial patterns did shift from the control pattern in the presence of reproductive cotton rats (Table 3). Spatial usage patterns with reproductive cotton rats were also different from those of nonreproductive tests.

Thus, the presence of cotton rats per se was not sufficient to shift prairie vole spatial usage from the pattern exhibited in control trials; reproductively active cotton rats induced a change in prairie voles' use of space while nonreproductive cotton rats did not.

There was no evidence of a difference in cotton rat spatial use between test procedures (Table 2), and we concluded that cotton rat spatial use was not significantly changed by the presence or absence of prairie voles (controls vs. reproductive or nonreproductive) or by the change in their own reproductive condition (reproductive vs. nonreproductive).

Behavioral interactions.-Interspecific behavioral interactions were classified as chases in which one animal pursued and the second retreated, or as avoidance in which the first animal detoured around or retreated from the second, usually after stopping or assuming an exploratory stance. The distance between the observer and the animals made it difficult to score low-intensity vocalizations, although studies in a small $(1 \mathrm{~m} \times 1 \mathrm{~m})$ arena indicated that vocalizations (probably tooth chattering) by voles were common when they could not avoid cotton rats. Other behaviors, such as "time together," "nasonasal contact," and "mutual upright" (Turner and Iverson 1973) were not observed interspecifically but did occur intraspecifically in both single species and multispecies tests.

Interspecific interactions were observed at low $(0.480 / \mathrm{h})$ but equal frequencies during both reproductive and nonreproductive tests. Thus, differences between test procedures occurred not in the rate of interactions but in their form (Fisher's exact test, $P=$ .021). During the reproductive tests there were six observations of cotton rats initiating chases but only one during the nonreproductive tests. In the nonreproductive tests, we observed 10 interactions in which prairie voles initiated avoidance behavior without overt aggression by cotton rats but only four such encounters in the reproductive tests.

During control tests only 2 of 18 Microtus and 1 of 18 Sigmodon sustained injuries from intraspecific interactions and most of these were minor tail wounds. During the nonreproductive tests neither cotton rats nor prairie voles showed any external injuries. During the reproductive tests, 1 of 9 cotton rats suffered a cut on the rear foot. For prairie voles, however, the frequency of wounding was elevated over both single species and nonreproductive tests. Of nine voles used, 
TABle 4. $M$. ochrogaster and $S$. hispidus activity (numbers observed) in the arena during reproductive and nonreproductive tests and comparisons of $M$. ochrogaster activity (numbers observed) during control (- Sigmodon) and reproductive and nonreproductive $(+$ Sigmodon $)$ tests. See Table 2 for explanations of terms.

\begin{tabular}{|c|c|c|c|c|}
\hline & \multicolumn{2}{|c|}{$\begin{array}{l}\text { Numbers } \\
\text { observed during } \\
\text { reproductive } \\
\text { (Allotopy) test }\end{array}$} & \multicolumn{2}{|c|}{$\begin{array}{c}\text { Numbers } \\
\text { observed during } \\
\text { nonreproductive } \\
\text { (Syntopy) test }\end{array}$} \\
\hline & Nocturnal & Diurnal & Nocturnal & Diurnal \\
\hline Sigm & 205 & 40 & 416 & 94 \\
\hline$M i$ & 172 & 70 & 94 & 197 \\
\hline \multicolumn{5}{|c|}{$\chi^{2}=11.052, \alpha<.005 \chi^{2}=194.416, \alpha<.005$} \\
\hline $\begin{array}{l}\text { (+) Sigmodon } \\
\text { (-) Sigmodon }\end{array}$ & $\begin{array}{l}172 \\
425\end{array}$ & $\begin{array}{r}70 \\
143\end{array}$ & $\begin{array}{r}94 \\
425\end{array}$ & $\begin{array}{l}197 \\
143\end{array}$ \\
\hline & \multicolumn{4}{|c|}{$1.231, \alpha<.500 \chi^{2}=145.481, \alpha<.005$} \\
\hline
\end{tabular}

one suffered rank II wounds, one rank III, and three rank IV wounds. Two of three voles which suffered rank IV wounds died after being returned to pretrial holding conditions. The vole with rank III wounds also died after being returned to isolation.

In addition to a greater frequency of wounding, prairie voles in the presence of reproductive cotton rats also tended to lose body mass. During the reproductive tests, prairie voles had mean body mass changes of $-2.1 \mathrm{~g} \pm 1.27 \mathrm{~g}(\bar{x} \pm \mathrm{SE} ; N=9)$, while during the nonreproductive tests prairie voles gained $2.3 \mathrm{~g} \pm 1.6$ g; $N=9$. Differences in body mass change between the test procedures were statistically significant (Wilcoxon two-sample test, $.025<P<.05$ ). During control tests, prairie voles showed an insignificant increase in mean body mass $(0.5 \mathrm{~g} \pm 1.03 \mathrm{~g} ; N=18)$.

Thus, reproductive cotton rats induced changes in the spatial usage patterns of prairie voles and were more aggressive towards prairie voles than were nonreproductive cotton rats. Prairie voles in the presence of reproductive cotton rats showed frequencies of wounding and mortality and loss of body mass which were not evident in the presence of conspecifics alone or nonreproductive cotton rats.

Temporal activity.-Given the similarities in spatial usage patterns between the laboratory and field studies, prairie vole temporal activity in the laboratory was expected to show similar patterns to the temporal data from the field. During reproductive (corresponding to times of allotopy) and nonreproductive (times of syntopy) tests there were significant differences in the proportions of cotton rats and prairie voles which were nocturnal or diurnal (Table 4). When relative frequencies of nocturnal and diurnal prairie voles during reproductive and control tests were compared, no significant difference was found (Table 4). Comparison of prairie vole activity during nonreproductive and control tests showed a significant difference in the proportion of diurnal and nocturnal prairie voles.

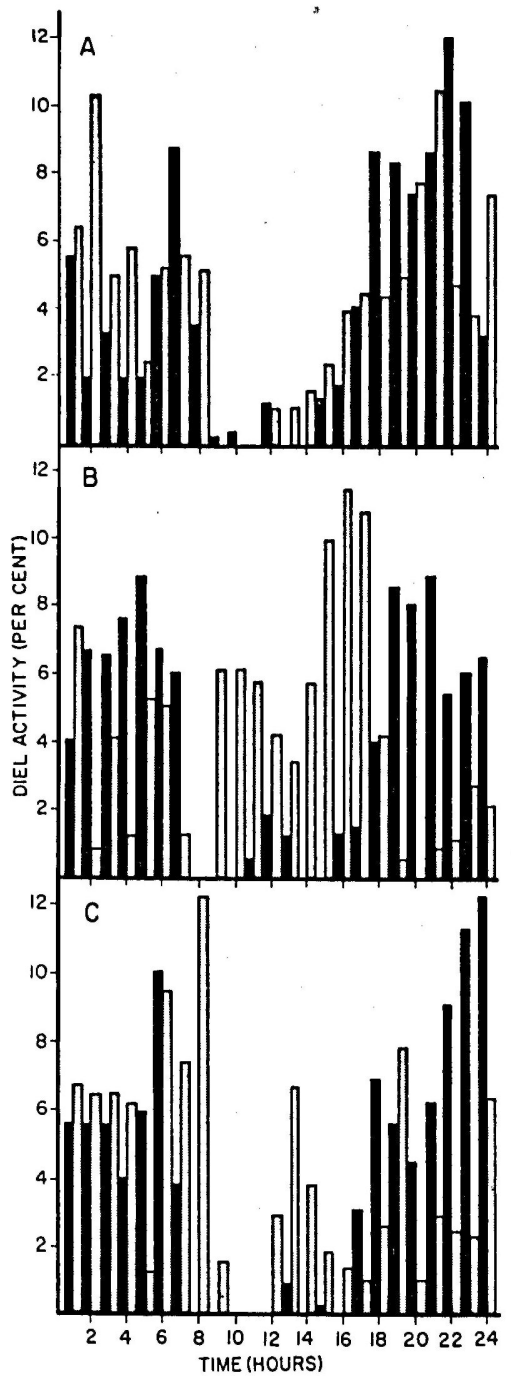

FIG. 4. Diel activity patterns of cotton rats (black bars) and prairie voles (gray bars) during arena studies for single species tests (A), nonreproductive tests (B), and reproductive tests (C).

The laboratory data were, therefore, in agreement with the field data. The proportions of nocturnal and diurnal cotton rats were different from the proportions of prairie voles. However, it was only during the nonreproductive tests, when prairie voles did not shift their spatial patterns, that there was evidence of a temporal shift in prairie vole activity. During the reproductive tests when prairie voles shifted their spatial distribution, increasing their activity in the areas least used by cotton rats, there was no evidence from the proportions of diurnal and nocturnal voles of a temporal shift in prairie vole activity,

Since temporal data from the laboratory were collected at hourly intervals, the data were reexamined to see if there might be a more finely scaled temporal division between prairie voles and cotton rats (Fig. 4A 
control tests, 4B nonreproductive tests, and $4 \mathrm{C}$ reproductive tests). During control tests both species showed broadly overlapping bimodal activity patterns with moderate levels of activity during daylight hours and peaks during dark hours similar to those described by Calhoun (1945). In the presence of nonreproductive cotton rats (Fig. 4B), when prairie voles did not shift spatial patterns, they underwent a major temporal shift in their activity and used the daylight hours when cotton rats were least active. During the reproductive tests (Fig. 4C) prairie voles were rarely active during the times of decreased cotton rat activity in the early afternoon hours. Rather, their activity was reduced during peak cotton rat activity times (late evening) and shifted to the early morning hours when cotton rats were moderately active $(2400-0700)$ or primarily inactive (0700-0800).

\section{Discussion}

The present study supports the hypothesis, based on earlier zoogeographic, ecological, and behavioral studies (Cockrum 1948, Martin 1956, Baker 1971, Terman 1974), that interspecific competition occurs between cotton rats and prairie voles. The data suggest that aggressive interference mediated by the reproductive condition of cotton rats is the form of interaction, and that the response of prairie voles is one of either temporal or spatial avoidance.

Spatial association of cotton rats and prairie voles in the field and laboratory shows a nonrandom seasonal pattern of spatial segregation and co-occurrence which is related to the cotton rat reproductive season (Fig. 2). The time lag between the onset of cotton rat reproductive activity and allotopy (Fig. 2) is expected under Terman's (1974) frequency of interspecific contact exclusion hypothesis. According to his hypothesis the rate of interspecific contact is an increasing function of the numbers of cotton rats. Thus, in April and early May there are too few cotton rats to induce spatial segregation by voles. Supporting Terman's hypothesis Glass and Slade (1980, in press) found a significant positive nonlinear correlation between the spatial association of cotton rats and prairie voles, and, the number of reproductive adult cotton rats $(R=$ .677 ). The difference in the prairie voles' response to reproductive and nonreproductive cotton rats appears related, in part, to differences in the levels of aggression of cotton rats. Changes in levels of aggression related to the secretion of reproductive hormones have been demonstrated in the laboratory for various small mammals (Beeman 1947, Tollman and King 1956, Vandenbergh 1971, Leshner 1978) and have been shown to be related to the annual reproductive cycle in the field (Sadleir 1965, Healey 1967, Turner and Iverson 1973, Turner et al. 1975). Terman (1978) has shown in field studies that prairie vole populations in the presence of reproductive cotton rats exhibit the same suite of characters we found in the arena voles exposed to reproductive cotton rats, i.e., decreased body mass, increased frequency of wounding and shifts in spatial distribution. Thus, it seems likely that the levels of cotton rat aggression increase with the onset of reproduction leading to the voles' avoidance of areas occupied by cotton rats.

The spatial pattern is not simply one of replacement described for other species of small mammals (King 1957, Kennerly 1959, Sheppe 1961, 1967, McCarley 1963, Cameron 1964, Koplin and Hoffmann 1968, Brown 1971, Heller 1971, Sheppard 1971, Grant 1972, Robertson 1975). Rather, there is a temporal (seasonal) component to the degree of spatial segregation. Seasonal allotopy has rarely been reported for small mammals. Iverson and Turner (1972) and Turner et al. (1975) examined the spatial distribution of Microtus pennsylvanicus and Clethrionomys gapperi which are allotopic when sympatric (Cameron 1964, Grant 1969, Morris 1969) and, either through naturally occurring absence or perturbations (Grant 1972), are known to occupy habitat that becomes available when the other species disappears. Iverson and Turner (1972) and Turner et al. (1975) found that, during the nonreproductive season, individuals of the two species mixed locally by moving into areas previously occupied exclusively by the other species. With the onset of reproduction, spatial segregation was restored. They correlated this seasonal pattern of spatial segregation to seasonal fluctuations in levels of intra- and interspecific aggression. Whether such seasonal shifts in spatial association are rare, or have merely been overlooked, needs further study.

During syntopy, prairie voles were primarily crepuscular and nocturnal, but in the absence of cotton rats their activity was more evenly distributed between day and night. If behavioral interactions in the laboratory are representative of field interactions, as the similarities in the spatio-temporal patterns and Terman's (1978) study suggest, why do prairie voles avoid cotton rats when cotton rats do not show overt signs of aggression? It may be that some low intensity threat or nonvisual communication is used and was not observed. Or, as Terman (1974) suggested, experienced voles (field caught adults, in this case) have learned to avoid cotton rats. Regardless of the cause for avoidance, the tendency remains in small mammals, for the larger member of interspecific pairs to be dominant (Grant 1969, Terman and Johnson 1971, Terman 1974, Ambrose and Meehan 1977, Petersen and Helland 1978, Randall 1978) and for the general interaction to be one of avoidance by subordinate individuals (Eisenberg 1963, Murie 1971, Turner and Iverson 1973, Ambrose and Meehan 1977, Petersen and Helland 1978, Randall 1978). Temporal avoidance of cotton rats by prairie voles permits prairie voles to use the entire habitat rather than the subset of the area 
they would be restricted to if spatial partitioning occurred. But why, then, do prairie voles not continue to partition the habitat temporally during the cotton rats' reproductive season? The answer probably lies in the inability of prairie voles to shift to diurnal activity during the cotton rats' reproductive season. It is likely that diurnal summer temperatures are too warm for prairie voles in northeastern Kansas. Microtines exposed to daytime summer temperatures are susceptible to heat stress (Jameson 1947, Martin 1956, Krebs et al. 1969, Wiegert 1972, Gaines and Rose 1976). In northeastern Kansas this includes June through September. Frequently no voles were captured during diurnal trap checks in June, July, and August while nearly all the diurnal vole captures during allotopy were from October through December when diurnal temperatures were cooler (Gaines and Rose 1976). Even following the disappearance of cotton rats in the field, prairie voles continued to use nocturnal hours rather than daylight hours during times cotton rats had been reproductive. During reproductive tests in the laboratory, prairie voles were only sporadically active during daylight hours. Their activity was reduced during times cotton rats were most active and was concentrated during times of moderate (2400-0600) to low (0700-0800) cotton rat activity but never shifted to daylight hours as seen in the nonreproductive tests. Whether this failure to shift activity pattern is related to endogenous or exogenous factors is unknown. Since voles are restricted to nocturnal activity during the cotton rats' reproductive season, they must risk at least moderate contact with aggressive cotton rats. In the laboratory, shifts in nocturnal activity did not eliminate aggressive interactions with the cotton rats.

Our suggestion that temporal avoidance should be preferred over spatial avoidance by prairie voles seems at odds with Schoener's (1974, page 33) argument that spatial partitioning. should be preferred over temporal partitioning since spatial partitioning allows "... a lowered but positive yield in the time period frequented by competitors . . ." compared to no yield at all for temporal inactivity. Schoener (1974) noted that the exception to this occurs "Only where the ability to process food is limited relative to risk of being eaten during feeding ..." The most likely resolution of these two conclusions is that Schoener (1974) intended his comments only for exploitative competition (sensu Miller 1969) rather than interference as we have implied for Sigmodon and Microtus. Schoener's conclusion for the preference of habitat partitioning over temporal partitioning should be modified to consider also avoidance of competitors who interact through interference rather than exploitation. Both voles and cotton rats eat vegetation (Fleharty and Olson 1969, Menhusen 1969) and the replacement rate is low enough that temporal partitioning does not actually reduce exploitative competition; it only avoids direct contact. A similar hypothesis has been advanced for temporal patterns of Sigmodon and Oryzomys (Kilduff and Dube 1979).

Numerous studies have invoked competition to explain differential use of resources by ecologically similar species (see Grant 1972, Diamond 1978 for examples). Yet, Connell (1975) and Wiens (1977) have argued that differential use of resources is not sufficient evidence for competition; both conclude that manipulative experiments are necessary. The present study illustrates this point. The spatial distribution of nonreproductive cotton rats and prairie voles in the laboratory arena were overlapping (Table 4) but significantly different ( $\alpha<.001$, two-way ANOVA) from one another. Given the similarities in diet (Fleharty and Olson 1969, Menhusen 1969), activity patterns (Fig. 4A; Calhoun 1945) and temperature tolerances (Wiegert 1972) one might conclude that differences in spatial use were a response to interspecific competitive pressures. However, when prairie vole spatial use was compared between control and nonreproductive tests there was no significant difference. Since the laboratory environment was artificial it could be argued that the results to not reflect the reality of a field environment. However, the artificial situation may be viewed as a strong point rather than a weakness of the design; the arena represented a novel environment for both species, and Schroder and Rosenzweig's (1975) argument that the absence of a spatial shift might be due to competitively induced evolutionary divergence of the species is unlikely to apply. Thus, although there were differences in spatial use by prairie voles and nonreproductive cotton rats, this alone was not evidence of competition.

If interspecific competition is defined (MacArthur 1972, Connell 1975) as a negative numerical response of a population to the presence of another species, then evidence such as mortality, wounding and mass loss found during the reproductive tests might be extrapolated to the population level. Although temporal shifts in prairie vole activity directly related to the presence of nonreproductive cotton rats occurred (Table 1, Fig. 4B), there was no evidence that could be extrapolated to the population level to indicate nonreproductive cotton rats had a negative impact on prairie voles. The only time cotton rats appeared to have a significant negative impact on the prairie vole population was from mid-May through December 1974, the period of allotopy, when the prairie vole population in the cotton rat habitat was lower than the vole population in the non-cotton rat habitat. From midMay through mid-December 1975 and 1976, following the cotton rat extinction, the prairie vole population in the cotton rat habitat equalled or exceeded the vole population in the non-cotton rat habitat. During syntopy the vole population in the cotton rat habitat was 
larger than the vole population in the non-cotton rat habitat, a pattern repeated following cotton rat extinction in 1975-1976. Thus, the period of increased cotton rat aggressiveness, high vole mortality and wounding in the lab, was accompanied by decreased vole populations in cotton rat habitat. During the period of low cotton rat aggression, vole populations were not suppressed by the presence of cotton rats.

Interspecific competition requires that the presence of each species produces a negative effect on the other. While the data indicate that cotton rats produce a negative effect on the prairie vole population, comparisons of cotton rat populations in the presence and absence of voles have yet to be done. Such a study may be difficult to perform since during their reproductive season, cotton rats tend to be spatially segregated from prairie voles. The negative impact of voles on cotton rats may be related to the energetics of reproduction in cotton rats which have been described by Randolph et al. (1977).

\section{Conclusions}

Our data support the hypothesis that cotton rats negatively affect prairie voles during at least a portion of the year. The method of interaction seems to be aggressive interference by cotton rats mediated by their reproductive cycle. Aggressive interference is a feasible tactic because low frequencies of aggressive interactions are sufficient to induce individual voles to shift their spatial usage patterns and the species use common runways (Jameson 1947, Martin 1956, Baker 1971 , Terman 1974) which increases the probability of interspecific encounters. Prairie voles, in general, show an avoidance reaction to cotton rats either through temporal or spatial shifts in their activity. Spatial shifts occur if voles are forced into contact with cotton rats and are prevented from shifting their temporal activity pattern. In the field this may be due to the voles' intolerance to high daytime temperatures. Changes in prairie vole numbers suggest a negative impact by cotton rats during allotopy but do not indicate a negative effect during syntopy when voles shift their temporal activity.

Competition, therefore, is likely to be an important component determining the dominant herbivore in small mammal communities where these species are sympatric. Thirty years of coexistence seems to have been insufficient, in this case, for evolutionary divergence of ecological strategies. As Martin (1956) noted, given reasonably high levels of overwinter survival, cotton rats restrict prairie voles to marginal habitat, which cotton rats do not use. At the present time their coexistence is probably a nonequilibrial phenomenon (MacArthur 1972, Connell 1975, 1978) relying on the seasonality of interactions, habitat heterogeneity and the prairie vole's greater range of habitat tolerances, for coexistence.

\section{ACKNOWLEDGMENTS}

We would like to thank B. A. Carnes, J. H. Honacki, and L. R. McClenaghan who helped with trapping during portions of the study. C. L. Baker, W. E. Duellman, M. S. Gaines, K. S. Harris, P. S. Humphrey, R. R. Patterson, and M. R. Terman loaned or donated various essential pieces of equipment. Our special appreciation goes to C. E. Brock, D. K. Bennett, J. D. Chorn, L. R. Heaney, G. W. Korch, J. T. Paul, E. C. Murphy, S. Richards, E. A. Rickart, C. J. Terry, and R. W. Turner for the many hours they contributed to the construction of the arena.

P. A. Kukuk, L. R. Heaney, L. R. McClenaghan, J. H. Honacki, and E. A. Rickart provided emotional support and stimulating discussions during the study. Their efforts were most welcome. M. S. Gaines, L. R. Heaney, R. S. Hoffmann, L. R. McClenaghan, and two anonymous reviewers read earlier drafts and made significant contributions.

Facilities on the Nelson Environmental Studies Area were provided by the Field Facilities Committee, University of Kansas. Computer time was from the University of Kansas Computation Center. Funding was provided, in part, by General Research Grants 3349-5038 and 3093-5038, University of Kansas to N.A. Slade and Graduate Teaching Funds from the Department of Systematics and Ecology to G. Schlager and J. W. Bee.

\section{Literature Cited}

Ambrose, R. F., and T. E. Meehan. 1977. Aggressive behavior of Perognathus parvus and Peromyscus maniculatus. Journal of Mammalogy 58:665-668.

Baker, R. H. 1971. Nutritional strategies of myomorph rodents in North American grasslands. Journal of Mammalogy 52:800-805.

Beeman, E. A. 1947. The effect of male hormone on aggressive behavior in mice. Physiological Zoology 20:373405.

Brown, J. H. 1971. Mechanisms of competitive exclusion between two species of chipmunks. Ecology 52:305-311.

Brown, J. H., and G. A. Lieberman. 1973. Resource utilization and coexistence of seed-eating desert rodents in sand dune habitats. Ecology 54:788-797.

Calhoun, J. B. 1945. Diel activity rhythms of the rodents, Microtus ochrogaster and Sigmodon hispidus. Ecology 26:251-273.

Cameron, A. W. 1964. Competitive exclusion between the rodent genera Microtus and Clethrionomys. Evolution 18:630-634.

Cameron, G. N. 1977. Experimental species removal: demographic reponses by Sigmodon hispidus and Reithrodontomys fulvescens. Journal of Mammalogy 58:488-506.

Cockrum, E. L. 1948. The distribution of the hispid cotton rat in Kansas. Transactions of the Kansas Academy of Science 51:306-312.

Cody, M. L. 1974. Competition and the structure of bird communities. Princeton University Press, Princeton, New Jersey, USA.

Connell, J. H. 1975. Some mechanisms producing structure in natural communities: a model and evidence from field experiments. Pages $460-490$ in M. L. Cody and J. M. Diamond, editors. Ecology and evolution of communities. Belknap Press, Cambridge, Massachusetts, USA.

2. 1978. Diversity in tropical rain forests and coral reefs. Science 199:1302-1310.

Conover, W. J. 1971. Practical nonparametric statistics. John Wiley and Sons, New York, New York, USA.

Diamond, J. M. 1978. Niche shifts and the rediscovery of interspecific competition. American Scientist 66:322-331.

Dunaway, P. B., and S. V. Kaye. 1961. Cotton rat mortality during severe winter. Journal of Mammalogy 42:265-268. 
Eisenberg, J. F. 1963. The behavior of heteromyid rodents. University of California Publications in Zoology 69, University of California Press, Berkeley, California, USA.

Fleharty, E. D., and L. E. Olson. 1969. Summer food habits of Microtus ochrogaster and Sigmodon hispidus. Journal of Mammalogy 50:475-486.

Frydendall, M. J. 1969. Rodent populations in four habitats in central Kansas. Transactions of the Kansas Academy of Science 72:213-222.

Gaines, M. S., and R. K. Rose. 1976. Population dynamics of Microtus ochrogaster in eastern Kansas. Ecology 57:1145-1161.

Gaines, M. S., A. M. Vivas, and C. L. Baker. 1979. An experimental analysis of dispersal in fluctuating vole populations: demographic parameters. Ecology 60:814-828.

Gause, G. F. 1934. The struggle for existence. Williams and Wilkins Company, Baltimore, Maryland, USA.

Glass, G. E., and N. A. Slade. 1980, in press. Population structure as a predictor of Sigmodon hispidus-Microtus ochrogaster spatial association. Journal of Mammalogy 61.

Grant, P. R. 1969. Experimental studies of competitive interactions in a two-species system. I. Microtus and Clethrionomys species in enclosures. Canadian Journal of Zoology 47:1059-1082.

- 1970. Experimental studies of competitive interactions in a two-species system. II. The behaviour of Microtus, Peromyscus and Clethrionomys species. Animal behaviour 18:411-426.

- 1971. Experimental studies of competitive interaction in a two-species system. III. Microtus and Peromyscus species in enclosures. Journal of Animal Ecology 40:323-350.

- 1972. Interspecific competition among rodents. Annual Review of Ecology and Systematics 3:79-106.

Hawes, M. L. 1977. Home range, territoriality, and ecological separation in sympatric shrews, Sorex vagrans and Sorex obscurus. Journal of Mammalogy 58:354-367.

Healey, M. C. 1967. Aggression and self-regulation of population size in deer mice. Ecology 48:377-392.

Heller, H. C. 1971. Altitudinal zonation of chipmunks ( $E u-$ tamias): interspecific aggression. Ecology 52:312-319.

Holbrook, S. J. 1978. Habitat relationships and coexistence of four sympatric species of Peromyscus in northwestern New Mexico. Journal of Mammalogy 59:18-26.

Husar, S. L. 1976. Behavioral character displacement: evidence of food partitioning in insectivorous bats. Journal of Mammalogy 57:331-338.

Hutchinson, G. E. 1959. Homage to Santa Rosalia, or why are there so many kinds of animals? American Naturalist 93:145-159.

Iverson, S. L., and B. N. Turner. 1972. Winter coexistence of Clethrionomys gapperi and Microtus pennsylvanicus in a grassland habitat. American Midland Naturalist 88:440 445.

Jameson, E. W. 1947. Natural history of the prairie vole (mammalian genus Microtus). University of Kansas Publications Museum of Natural History 1:125-151.

Joule, J., and G. N. Cameron. 1975. Species removal studies. I. Dispersal strategies of sympatric Sigmodon hispidus and Reithrodontomys fulvescens populations. Journal of Mammalogy 56:378-396.

Kennerly, T. E., Jr. 1959. Contact between the ranges of two allopatric species of pocket gophers. Evolution 13:247-263.

Kilduff, T. S., and M. G. Dube. 1979. The effects of seasonal photoperiods on activity of cotton rats and rice rats. Journal of Mammalogy 60:169-176.

King, J. A. 1957. Intra- and interspecific conflict of $M u s$ and Peromyscus. Ecology 38:355-357.

Koplin, J. R., and R. S. Hoffmann. 1968. Habitat overlap and competitive exclusion in voles (Microtus). American Midland Naturalist 80:894-507.

Krebs, C. J. 1977. Competition between Microtus pennsylvanicus and Microtus ochrogaster. American Midland Naturalist 97:42-49.

Krebs, C. J., B. L. Keller, and R. H. Tamarin. 1969. Microtus population biology: demographic changes in populations of $M$. ochrogaster and $M$. pennsylvanicus in southern Indiana. Ecology 50:587-607.

Krebs, C. J., I. Wingate, J. LeDuc, J. A. Redfield, M. Taitt, and R. Hilborn. 1976. Microtus population biology: dispersal in fluctuating populations of $M$. townsendii. Canadian Journal of Zoology 54:79-95.

Leshner, A. I. 1978. An introduction to behavioral endocrinology. Oxford University Press, New York, New York, USA.

Lidicker, W. Z., Jr. 1975. The role of dispersal in the demography of small mammals. Pages 103-128 in F. B. Golley, K. Petrusewiez and L. Ryszkowski, editors. Small mammals: their productivity and population dynamics. Cambridge University Press, Cambridge, England.

Lotka, A. J. 1925. Elements of physical biology. Williams and Wilkins Company, Baltimore, Maryland, USA.

MacArthur, R. H. 1969. Species packing and what competition minimizes. Proceedings of the National Academy of Sciences of the USA 64:1369-1371.

. 1972. Geographical ecology. Harper and Row, New York, New York, USA.

MacArthur, R. H., and R. Levins. 1964. Competition, habitat selection, and character displacement in a patchy environment. Proceedings of the National Academy of Science of the USA. 51:1207-1210.

MacArthur, R. H., and R. Levins. 1967. The limiting similarity, convergence, and divergence of coexisting species. American Naturalist 101:377-385.

Martin, E. P. 1956. A population study of the prairie vole (Microtus ochrogaster) in northeastern Kansas. University of Kansas Publications Museum of Natural History 8:361416.

McCarley, H. 1963. Distributional relationships of sympatric populations of Peromyscus leucopus and P. gossypinus. Ecology 44:784-788.

M'Closkey, R. T. 1976. Community structure in sympatric rodents. Ecology 57:728-739.

M'Closkey, R. T., and B. Fieldwick. 1975. Ecological separation of sympatric rodents (Peromyscus and Microtus). Journal of Mammalogy 56:119-129.

Menhusen, B. R. 1969. An investigation on the food habits of four species of rodents in captivity. Transactions of the Kansas Academy of Science 66:107-112.

Miller, R. S. 1969. Competition and species diversity. Brookhaven Symposia in Biology 22:63-70.

Morris, R. D. 1969. Competitive exclusion between Microtus and Clethrionomys in the aspen parkland of Saskatchewan. Journal of Mammalogy 50:291-301.

Morris, R. D., and P. R. Grant. 1972. Experimental studies of competitive interaction in a two species system. IV. Microtus and Clethrionomys species in a single enclosure. Journal of Animal Ecology 41:275-290.

Murie, J. O. 1971. Dominance relationships between Peromyscus and Microtus in captivity. American Midland Naturalist 86:229-231.

Myers, J. H., and C. J. Krebs. 1971. Genetic, behavioral, and reproductive attributes of dispersing field voles Microtus pennsylvanicus and Microtus ochrogaster. Ecological Monographs 41:53-78.

Peters, R. H. 1976. Tautology in evolution and ecology. American Naturalist 110:1-12.

Petersen, M. K. 1973. Interactions between the cotton rats, 
Sigmodon fulviventer and S. hispidus. American Midland Naturalist 90:319-333.

Petersen, M. K., and M. J. Helland. 1978. Behavioral interactions in Sigmodon fulviventer and $S$. hispidus. Journal of Mammalogy 59:118-124.

Pianka, E. R. 1974. Evolutionary ecology. Harper and Row, New York, New York, USA.

Randall, J. A. 1978. Behavioral mechanisms of habitat segregation between sympatric species of Microtus: habitat preference and interspecific dominance. Behavioral Ecology and Sociobiology 3:187-202.

Randolph, P. A., J. C. Randolph, K. Mattingly, and M. M. Foster. 1977. Energy costs of reproduction in the cotton rat, Sigmodon hispidus. Ecology 58:31-45.

Robertson, P. B. 1975 . Reproduction and community structure of rodents over a transect in southern Mexico. Dissertation. University of Kansas, Lawrence, Kansas, USA.

Rohlf, F. J., and R. R. Sokal. 1969. Statistical tables. W. H. Freeman, San Francisco, California, USA.

Rose, R. K. 1973. A small mammal live trap. Transactions of the Kansas Academy of Science 76:14-17.

Rosenzweig, M. L., and J. Winakur. 1969. Population ecology of desert rodent communities: habitats and environmental complexity. Ecology 50:558-572.

Sadleir, R. M. F. S. 1965. The relationship between agonistic behaviour and population changes in the deermouse, Peromyscus maniculatus (Wagner). Journal of Animal Ecology 34:331-352.

Schoener, T. W. 1974. Resource partitioning in ecological communities. Science 185:27-38.

Schroder, G. D., and M. L. Rosenzweig. 1975. Perturbation analysis of competition and overlap in habitat utilization between Dipodomys ordii and Dipodomys merriami. Oecologia 19:9-28.

Sheppard, D. H. 1971. Competition between two chipmunk species (Eutamias). Ecology 52:320-329.

Sheppe, W. 1961. Systematic and ecological relations of Peromyscus oreas and $P$. maniculatus. Proceedings of the American Philosophical Society 105:421-446.

1967. Habitat restriction by competitive exclusion in the mice Peromyscus and Mus. Canadian Field-Naturalist 81:81-98.

Tamarin, R. H. 1978. Dispersal, population regulation, and K-selection in field mice. American Naturalist 112:545555.

Terman, M. R. 1974. Behavioral interactions between Microtus and Sigmodon: a model for competitive exclusion. Journal of Mammalogy 55:705-719.

1978. Population dynamics of Microtus and Sigmodon in central Kansas. Transactions of the Kansas Academy of Science 81:337-351.

Terman, M. R., and D. I. Johnson. 1971. The effects of Sigmodon hispidus on Microtus pennsylvanicus in a con. fined area. Transactions of the Kansas Academy of Science 74:217-220.

Tollman, J., and J. A. King. 1956. The effects of testosterone propionate on aggression in male and female C57BU 10 mice. Animal Behaviour 4:147-149.

Turner, B. N., and S. L. Iverson. 1973. The annual cycle of aggression in male Microtus pennsylvanicus, and its relation to population parameters. Ecology 54:967-981.

Turner, B. N., M. R. Perrin, and S. L. Iverson. 1975. Winter coexistence of voles in spruce forest: relevance of seasonal changes in aggression. Canadian Journal of Zoology 53:1004-1011.

Vandenbergh, L. G. 1971. The effects of gonadal hormones on the aggressive behaviour of adult golden hamsters (Me. socricetus auratus). Animal Behaviour 19:589-594.

Volterra, V. 1926. Fluctuations in the abundance of a species considered mathematically. Nature 118:558-560.

Whitford, W. G. 1976. Temporal fluctuations in density and diversity of desert rodent populations. Journal of Mammalogy 57:351-369.

Wiegert, R. G. 1972. Population dynamics of cotton rats (Sigmodon hispidus) and meadow voles (Microtus pennsylvanicus) in field enclosures in South Carolina. Bulletin of the Georgia Academy of Science 30:103-110.

Wiens, J. A. 1977. On competition and variable environments. American Scientist 65:590-597. 